Nevşehir Bilim ve Teknoloji Dergisi TARGíd Özel Sayı 150-160 2016

DOI: 10.17100/nevbiltek.210981

URL: http://dx.doi.org/10.17100/nevbiltek.210981

\title{
Fosfor Uygulamasının Marul ve Soğan Bitkilerinin Mineral Element Konsantrasyonlarına Etkisi
}

\author{
Özge Şahin ${ }^{*}$, Mehmet Burak Taşkın, Emre Can Kaya \\ Ankara Üniversitesi, Ziraat Fakültesi, Toprak Bilimi ve Bitki Besleme Bölümü, Ankara
}

Öz

Marul (Lactuca sativa L.) ve soğan (Allium cepa L.) bitkilerinin gelişimi ve mineral element alımına fosfor (P) uygulamasının etkisini araştırmak üzere Triple süper fosfat (TSP, \%42 $\mathrm{P}_{2} \mathrm{O}_{5}$ ) gübresinden 0, 50, 100, 200, $400 \mathrm{mg} \mathrm{kg}^{-1} \mathrm{P}$ uygulanmıştır. Marul bitkisinde en yüksek kuru ağırlığa $50 \mathrm{mg} \mathrm{kg}^{-1} \mathrm{P}$ düzeyinde ulaşılırken, soğan bitkisinde $200 \mathrm{mg} \mathrm{kg}^{-1} \mathrm{P}$ düzeyinde ulaşılmıştır. Artan miktarda uygulanan fosfor ile marul bitkisinin $\mathrm{P}, \mathrm{Br}, \mathrm{Rb}$ konsantrasyonlarının arttı̆̆ı, $\mathrm{Ca}, \mathrm{S}, \mathrm{Fe}, \mathrm{Zn}, \mathrm{Mn}, \mathrm{Ti}, \mathrm{Sr}$ ve $\mathrm{Ba}$ konsantrasyonlarının azaldığı belirlenmiştir. Fosfor uygulamasına bağlı olarak bitkilerin Si ve Ni konsantrasyonlarında önemli bir değişim olmamıştır. Artan düzeyde uygulanan fosfora bağlı olarak soğan bitkisinin $\mathrm{P}, \mathrm{As}, \mathrm{Rb}, \mathrm{Ba}$ konsantrasyonları artarken $\mathrm{Cu}, \mathrm{Ti}$ ve Co konsantrasyonları azalmıştır. Fosfor uygulaması, soğan bitkisinin K ve S konsantrasyonunu artırmış̧ır. Marul bitkisinin K konsantrasyonuna etkisi istatistik olarak önemsiz olurken yüksek P düzeyleri S konsantrasyonunu azaltmıştır. Her iki bitkinin Fe konsantrasyonu P uygulamasına bağlı olarak azalmıştır. En yüksek Br konsantrasyonu her iki bitkide de $400 \mathrm{mg} \mathrm{kg}^{-1} \mathrm{P}$ uygulamasında belirlenmiştir. Artan düzeyde uygulanan fosfor ile bitkilerin özellikle bitkiler için mutlak gerekli olmayan mineral konsantrasyonlarının arttı̆̆ bu artışın çevre kirliliğinin yanı sıra insan sağlığını olumsuz etkileyebileceği için aşırı fosforlu gübre kullanımından kaçınılması gerektiği sonucuna ulaşılmıştır.

Anahtar Kelimeler: marul, soğan, fosfor, mineral element

\section{The Effect of Phosphorus Application on Mineral Elements Concentration of Lettuce and Onion Plants}

Abstract

In this experiment, effect of phosphorus applications at the levels of 0, 50, 100, 200, $400 \mathrm{mg} \mathrm{P} \mathrm{kg}^{-1}$ (as triplesuperphosphate, 42\% $\mathrm{P}_{2} \mathrm{O}_{5}$ ) on the growth and mineral composition of lettuce (Lactuca sativa L.) and onion (Allium cepa L.) plants were studied. The highest dry weight of lettuce and onion were found at $50 \mathrm{mg} \mathrm{P} \mathrm{kg}^{-1}$ and $200 \mathrm{mg} \mathrm{P} \mathrm{kg}{ }^{-1}$, respectively. Lettuce plant $\mathrm{P}$, Br, Rb concentrations increased and $\mathrm{Ca}, \mathrm{S}, \mathrm{Fe}, \mathrm{Zn}, \mathrm{Mn}$, Ti, Sr and Ba concentrations decreased with increasing amounts of phosphorus application and also there is no significant difference on $\mathrm{Si}$ and $\mathrm{Ni}$ concentrations. On the other hand, the concentration of $\mathrm{P}$, As, Rb and $\mathrm{Ba}$ were increased and $\mathrm{Cu}, \mathrm{Ti}$ and $\mathrm{Co}$ decreased by increasing $\mathrm{P}$ application in onion plants. Phosphorus application significantly increased K and S concentations of onion. There is no difference on K concentration of lettuce. Sulphur concentration of lettuce was decreased by increasing $\mathrm{P}$ levels. Iron concentration of both plants were lower in $\mathrm{P}$ applied plants. The highest Br concentration of both plants were determined at the level of $400 \mathrm{mg} \mathrm{P} \mathrm{kg}{ }^{-1}$ application. In conclusion, non-essential element concentrations enhanced with increasing application of P. This may cause environmental pollution and also affect human health unfavourably. Hence, it was concluded to avoid excessive P fertilizer using.

Keywords: Lettuce, onion, phosphorus, mineral elements

*e-mail: osahin@ankara.edu.tr 


\section{Giriș}

Toplam fosfor, ortalama olarak yer kürenin üst kabuğunda $\% 0.1$ [1 ve 2] topraklarda ise $\% 0.02$ $\% 0.15$ [3] düzeyinde bulunmaktadır. Çözünebilir ve bitkiye yarayışlı $\mathrm{P}$ ise daha düşük düzeylerdedir [4]. Türkiye tarım topraklarının \%58'inde bitkiye yarayışlı fosforun yetersiz düzeyde olduğunu belirtmiştir. Orta ve Doğu Karadeniz' de yarayışlı fosforun \%35.71 çok az düzeyde olduğu ve diğer bölgelere ait çalışmaların devam ettiği belirtilmiştir [5]. Fosforun tarım topraklarındaki miktarının genellikle az olması, Türkiye'nin içinde bulunduğu iklim kuşağı, jeolojik yapısı ve coğrafi konumundan kaynaklanmaktadır [2]. Toprak sıcaklığının fazlalığı nem içeriğinin azlığı, strüktürün bozuk olması ve organik madde miktarının azlığının yanı sıra özellikle yüksek pH ve kireçli topraklarda fosforun büyük bir kısmının kalsiyum fosfat ve pH'sı düşük topraklarda demir ve alüminyum fosfat şeklinde bitkilerin yararlanamayacağı formlarda tutulmasına yol açmakta ve topraklarda fosforun bitkilere yarayışlılığını önemli ölçüde sınırlamaktadır [2], [5-9].

Topraklarda bitkiye yarayışlı fosfor miktarının düşük olması nedeniyle fosforlu gübre kullanımı her geçen gün arttığından, fosforlu gübre üretiminde kullanılan fosfor rezervleri gün geçtikçe azalmaktadır [2 ve10]. Diğer bitki besin elementlerinden farklı olarak, uygulanan fosforun büyük bir bölümü toprak tarafindan tutulmakta ve toprağa uygulanan fosforlu gübrelerin $\% 80$ 'inden fazlas1 bitkilerin alamayacağı forma dönüşmesi nedeniyle toprağa uygulanan fosforlu gübrelerin ancak \%525'inden bitkiler yararlanabilmektedir. Bu durum fosforlu gübrelerin fazla miktarda tüketilmesine neden olmaktadır [2], [11-17].

Tarım topraklarındaki toksik metallerin en önemli kaynaklarından biri fosforlu gübrelerdir. Fosforlu gübrelerdeki bu metallerin varlığı ve miktarı kaya fosfatların metal konsantrasyonlarına bağlı olarak değişmektedir [18]. Fosfat kayası olarak bilinen ham fosfat ya da kaya fosfat, fosforlu gübrelerin ana maddesidir. Doğada genellikle apatit $\left[\mathrm{Ca}_{10}\left(\mathrm{PO}_{4}\right) 6\left(\mathrm{~F}_{2}, \mathrm{Cl}_{2},(\mathrm{OH})_{2}, \mathrm{CO}_{3}\right.\right.$ ve $\left.\mathrm{SO}_{4}\right]$ formunda bulunan ve içeriğindeki anyon ve katyona göre karbonat apatit, flor apatit, klor apatit, hidroksi apatit ve sülfat apatit diye adlandırılan kaya fosfatlardan gübre üretiminde en fazla kullanılanı flor apatittir [18]. Yapılan araştırmalar sonucunda fosforlu gübre uygulaması ile toprakların $\mathrm{Cu}, \mathrm{Cr}, \mathrm{Pb}, \mathrm{Cd}, \mathrm{Hg}, \mathrm{Zn}, \mathrm{As}, \mathrm{Cr}, \mathrm{Se}$ konsantrasyonlarının artabileceği, toprak kökenli bu kirlenmenin besin zinciri yolu ile insan sağlığı açısından tehdit oluşturabileceği belirlenmiştir [19-22].

Bu çalışma ile Türkiye'de yaygın ve yer yer aşırı miktarlarda kullanılan fosforlu gübrenin soğan ve marul bitkilerinin mutlak gerekli olan ve olmayan mineral element konsantrasyonları üzerine etkileri belirlenmiştir.

\section{Materyal ve Metot}

$\mathrm{Bu}$ araştırmada marul (Lactuca sativa L.) ve soğan (Allium cepa L.) bitkileri test bitkisi olarak kullanılmıştır. Fosfor kaynağı olarak \% 42'lik TSP (Triplesüperfosfat) gübresi kullanılmış ve saksılara 0 , 50, 100, 200 ve $400 \mathrm{mg} \mathrm{kg}^{-1} \mathrm{P}$ düzeyinde uygulanmıştır.

Marul bitkisi ile yapılan deneme $6 \mathrm{~kg}$, soğan bitkisi ile yapılan deneme ise $2 \mathrm{~kg}$ toprak doldurulmuş saksılarda 3 tekrarlı olarak tesadüf parselleri deneme desenine göre yürütülmüştür. Marul bitkisi, her saksıya 25 adet Yedi kule marul tohumu olacak şekilde, soğan bitkisi ise her saksıda 10 arpacık soğanı 
olacak şekilde ekilmiştir. Her iki bitkinin ekimi 06.03.2013 tarihinde yapılmıştır. Marul bitkisi, 25.03.2013 tarihinde her saksıda 10 bitki, soğan bitkisi ise 16.03.2013 tarihinde her saksıda 8 bitki kalacak şekilde seyreltilmiştir. Marul ve soğan bitkilerine temel gübreleme amacıyla 31.03.2013 ve 02.04.2013 tarihinde $200 \mathrm{mg} \mathrm{kg}^{-1} \mathrm{~N}$ (amonyum nitrat) uygulanmıştır. Deneme süresince saksıların su faktörünün optimum düzeyde tutulmasına çalışılmış ve bu amaçla deneme toprağının tarla kapasitesi belirlenmiştir [23]. Buna göre saksılara, tarla kapasitesi $\% 75^{\prime}$ e gelinceye kadar tartılarak su ilave edilmiştir. Marul bitkisi gelişmesinin 54 gününde, soğan bitkisi ise gelişmesinin 56 gününde hasat edilmiștir.

Hasattan sonra bitkiler bulaşmayı önlemek amacıyla yıkanmış ve havalı kurutma dolabında 65 ${ }^{\circ} \mathrm{C}$ 'de sabit ağırlığa gelinceye kadar kurutulmuştur. Kurutulan bitkilerin kuru ağırlıkları belirlendikten sonra IKA marka öğütücü ile öğütülmüş ve aşağıda belirtildiği şekilde $\mathrm{P}, \mathrm{K}, \mathrm{Ca}, \mathrm{Mg}, \mathrm{S}, \mathrm{Fe}, \mathrm{Cu}, \mathrm{Mn}$ ve $\mathrm{Zn}$ gibi mutlak gerekli besin elementlerin yanı sıra mutlak gerekli olmayan mineral elementlerin $(\mathrm{Na}, \mathrm{Si}, \mathrm{Al}$, $\mathrm{Co}, \mathrm{Ni}, \mathrm{As}, \mathrm{Rb}, \mathrm{SR}, \mathrm{Br}$ ) konsantrasyonları belirlenmiştir.

\section{Deneme Toprağının Fiziksel ve Kimyasal Analizlerinde Uygulanan Yöntemler}

Denemede kullanılan toprak, A.Ü. Ziraat Fakültesi Toprak Bölümü deneme alanından $\left(39^{\circ} 57^{\prime} 44.51^{\prime \prime} \mathrm{K}\right.$; $\left.32^{\circ} 51^{\prime} 46.95^{\prime \prime} \mathrm{D}\right)$ alınmış İnceptisol ordosuna ait bir topraktır. Toprak örneği laboratuvarda hava kuru duruma getirilip, 2 mm'lik elekten geçirildikten sonra aşağıda belirtilen fiziksel ve kimyasal analizlere tabi tutulmuştur [24].

Tekstür: Denemede kullanılan toprağın kum, silt ve kil fraksiyonları [25] tarafından bildirildiği şekilde hidrometre yöntemine göre belirlenmiş, tekstür sınıfı belirlenmiştir [26].

Toprak reaksiyonu (pH): 1:2.5 toprak:su karışımında cam elektrotlu Mettler-Toledo marka pH-metre ile belirlenmiştir [27].

Elektriksel iletkenlik (EC): Elektriksel iletkenlik değeri 1:2.5 oranında saf su ile sulandırılmış toprak EC metre ile belirlenmiştir [28].

Tarla Kapasitesi: Toprak örneğinin tarla kapasitesi yöntem II ile belirlenmiştir [23].

Organik madde: Walkley-Black yaş yakma yöntemine göre belirlenmiştir [27].

Toplam Kireç: Scheibler kalsimetresiyle belirlenmiștir [29].

Toplam azot (N): Kjeldahl yöntemine göre belirlenmiştir [30].

Yarayış̧ı fosfor (P): Toprak örneklerinde fosfor, $0.5 \mathrm{M} \mathrm{NaHCO}_{3}$ (pH: 8.5) ile ekstrakte edilmiş, çözeltiye geçen fosfor (P), molibdofosforik mavi renk yöntemine göre Shimadzu model UV 1210 spektrofotometrede belirlenmiştir [31].

Değişebilir potasyum (K), sodyum (Na), kalsiyum (Ca) ve magnezyum (Mg): Denemede kullanılan toprak $1.0 \mathrm{~N}$ nötr (pH: 7.0) amonyum asetat $\left(\mathrm{CH}_{3} \mathrm{COONH}_{4}\right)$ ile ekstrakte edilmiş, süzükteki potasyum $(\mathrm{K})$, sodyum (Na), kalsiyum (Ca) ve magnezyum (Mg) ICP-OES (Perkin Elmer 2100V) cihazı ile belirlenmiştir [32].

Yarayışılı demir (Fe), çinko (Zn), bakır (Cu) ve mangan (Mn): Deneme kullanılan toprak, çözelti oranı 1:2 olacak şekilde $0.005 \mathrm{M}$ DTPA (dietilentriaminpenta asetik asit) $+0.01 \mathrm{M} \mathrm{CaCl}_{2}+0.1 \mathrm{M}$ TEA (trietanolamin) karışım çözeltisi (pH: 7.3) ile 2 saat çalkalanarak ekstrakte edilen süzükte $\mathrm{Fe}, \mathrm{Zn}, \mathrm{Cu}$ ve Mn ICP-OES (Perkin Elmer 2100V) cihazı ile belirlenmiştir [33]. 
Deneme Toprağı ile Marul ve Soğan Bitkilerinin Mutlak Gerekli Olmayan Mineral Element Konsantrasyonlarının PEDXRF ile Belirlenmesi

Araştırma toprağının $\mathrm{Na}, \mathrm{Al}, \mathrm{Si}, \mathrm{Cl}, \mathrm{Ti}, \mathrm{Vn}, \mathrm{Cr}, \mathrm{Ni}, \mathrm{Co}, \mathrm{As}, \mathrm{Br}, \mathrm{Rb}, \mathrm{Sr}, \mathrm{Zr}, \mathrm{Ba}, \mathrm{La}, \mathrm{Pb}$ konsantrasyonları ile bitki örneklerinin $\mathrm{Na}, \mathrm{Si}, \mathrm{Al}, \mathrm{Ti}, \mathrm{Co}, \mathrm{Ni}, \mathrm{As}, \mathrm{Br}, \mathrm{Rb}, \mathrm{Sr}, \mathrm{Cd}, \mathrm{Ba}, \mathrm{Th}$ ve U konsantrasyonları belirlenmiştir. Elenmiş toprak örneği ile öğütülmüş bitki örnekleri bağlayıcı olarak mum kullanılarak ve pres makinasında preslenerek $32 \mathrm{~mm}$ kalınlı̆̆ında peletlenmiştir. USGS (United States Geological Survey) standartlarından GBW-7109 ve GBW-7309 sediment standartları referans madde olarak kullanılmak üzere örnekteki işleme benzer işlemler uygulanarak peletlenmiş ve analiz kalite kontrolü amacıyla kullanılmıştır. PEDXRF ile mineral element analizleri yapılmıştır [34 ve35]. Analizde kullanılan cihaz, spektrometresi Spectro XLAB 2000 olan Rh anoduna sahip X-Işını tüpü ve $0.5 \mathrm{~mm}$ yandan Be camlı PEDXRF spektrometresidir. Spektrometrenin algılayıcısı sıvı $\mathrm{N}_{2}$ ile soğutulmuş çözünürlüğü Mn Ko, 5000 cps’da <150eV olan Si (Li)’dur. Spektrometrede, d tümü ortak olarak ortogonal açıda olmak üzere 1şık kaynağı olarak; dağınık 1şık olarak ve floresans 1şı̆̆ı olarak ayarlanmıştır. PEDXRF’te örnek ölçümleri Barkla ( $Z>22$ olan elementler için uygun olan), Bragg ( $Z$ değeri 22'ye kadar olan elementler için uygun olan uyarlanmış kristal hedefli) ve özel elementler ya da az sayıdaki ardışık elementler için saf metalleri belirlemek üzere 3 farklı hedefe yönelik yapılmıştır. Buradaki son hedef matriks düzeltmeyi yapabilmek amacıyla Compton 1şık saçılımını oluşturmak üzere kullanılmıştır [36].

\section{Bulgular}

Denemede kullanılan toprağın bazı fiziksel ve kimyasal özellikleri Tablo 1'de verilmiştir.

Tablo1. Deneme toprağının bazı fiziksel ve kimyasal özellikleri

\begin{tabular}{|c|c|}
\hline Özellikler (Method ) & Toprak \\
\hline Tarla Kapasitesi & $240 \mathrm{~g} \mathrm{~kg}^{-1}$ \\
\hline Tekstür & Killi Tın \\
\hline $\mathrm{CaCO}_{3}(\%)$ & 5.73 \\
\hline $\mathrm{pH}(1: 2.5 \mathrm{su})$ & 7.98 \\
\hline EC $(1: 2.5 \mathrm{su})$ & $0.44 \mathrm{dSm}^{-1}$ \\
\hline Organik Madde & $7.60 \mathrm{~g} \mathrm{~kg}^{-1}$ \\
\hline Toplam-N (Kjeldahl) & $0.92 \mathrm{~g} \mathrm{~kg}^{-1}$ \\
\hline $\mathrm{K}$ ( $\mathrm{NH}_{4} \mathrm{OAc}-\mathrm{eks}$.) & $0.47 \mathrm{~g} \mathrm{~kg}^{-1}$ \\
\hline Toplam-K (X-RF) & $14.7 \mathrm{~g} \mathrm{~kg}^{-1}$ \\
\hline $\mathrm{Ca}$ ( $\mathrm{NH}_{4} \mathrm{OAc}$-eks.) & $2.56 \mathrm{~g} \mathrm{~kg}^{-1}$ \\
\hline Toplam-Ca (X-RF) & $33.8 \mathrm{~g} \mathrm{~kg}^{-1}$ \\
\hline $\mathrm{Na}\left(\mathrm{NH}_{4} \mathrm{OAc}\right.$--eks. $)$ & $64.0 \mathrm{mg} \mathrm{kg}^{-1}$ \\
\hline Toplam-Na (X-RF) & $0.29 \mathrm{~g} \mathrm{~kg}^{-1}$ \\
\hline $\mathrm{P}\left(\mathrm{NaHCO}_{3}\right.$-alınabilir) & $8.54 \mathrm{mg} \mathrm{kg}^{-1}$ \\
\hline Toplam-P (X-RF) & $0.76 \mathrm{~g} \mathrm{~kg}^{-1}$ \\
\hline Zn (DTPA-eks.) & $0.72 \mathrm{mg} \mathrm{kg}^{-1}$ \\
\hline Toplam Zn (X-RF) & $77.2 \mathrm{mg} \mathrm{kg}^{-1}$ \\
\hline Fe (DTPA-eks.) & $6.36 \mathrm{mg} \mathrm{kg}^{-1}$ \\
\hline Toplam-Fe (X-RF) & $38.9 \mathrm{~g} \mathrm{~kg}^{-1}$ \\
\hline Cu (DTPA-eks.) & $1.01 \mathrm{mg} \mathrm{kg}^{-1}$ \\
\hline
\end{tabular}


Şahin Ö., Taşkın MB., Kaya EC.

\begin{tabular}{ll}
\hline Toplam-Cu (X-RF) & $33.7 \mathrm{mg} \mathrm{kg}^{-1}$ \\
Mn (DTPA-eks.) & $24.0 \mathrm{mg} \mathrm{kg}^{-1}$ \\
Toplam-Mn (X-RF) & $0.76 \mathrm{~g} \mathrm{~kg}^{-1}$ \\
Toplam-S (X-RF) & $0.46 \mathrm{~g} \mathrm{~kg}^{-1}$ \\
Toplam-Mo (X-RF) & $4.40 \mathrm{mg} \mathrm{kg}^{-1}$ \\
Toplam-Mg (X-RF) & $11.5 \mathrm{~g} \mathrm{~kg}^{-1}$ \\
Toplam-Al (X-RF) & $51.8 \mathrm{~g} \mathrm{~kg}^{-1}$ \\
Toplam-Si (X-RF) & $178.1 \mathrm{~g} \mathrm{~kg}^{-1}$ \\
Toplam-Cl (X-RF) & $0.58 \mathrm{~g} \mathrm{~kg}^{-1}$ \\
Toplam-Ti (X-RF) & $4.53 \mathrm{~g} \mathrm{~kg}^{-1}$ \\
Toplam-V (X-RF) & $0.12 \mathrm{mg} \mathrm{kg}^{-1}$ \\
Toplam-Cr (X-RF) & $0.15 \mathrm{mg} \mathrm{kg}^{-1}$ \\
Toplam-Ni (X-RF) & $63.9 \mathrm{mg} \mathrm{kg}^{-1}$ \\
Toplam-Co (X-RF) & $28.0 \mathrm{mg} \mathrm{kg}^{-1}$ \\
Toplam-As (X-RF) & $19.1 \mathrm{mg} \mathrm{kg}^{-1}$ \\
Toplam-Br (X-RF) & $4.20 \mathrm{mg} \mathrm{kg}^{-1}$ \\
Toplam-Rb (X-RF) & $65.8 \mathrm{mg} \mathrm{kg}^{-1}$ \\
Toplam-Sr (X-RF) & $273 \mathrm{mg} \mathrm{kg}^{-1}$ \\
Toplam-Zr (X-RF) & $191 \mathrm{mg} \mathrm{kg}^{-1}$ \\
Toplam-Ba (X-RF) & $459 \mathrm{mg} \mathrm{kg}^{-1}$ \\
Toplam-La(X-RF) & $29.3 \mathrm{mg} \mathrm{kg}^{-1}$ \\
Toplam-Pb (X-RF) & $26.6 \mathrm{mg} \mathrm{kg}^{-1}$ \\
\hline
\end{tabular}

Tablo 2. Artan düzeyde uygulanan fosforun marul ve soğan bitkilerinin kuru ağırlığı üzerine etkisi

\begin{tabular}{ccc}
\hline Bitki & $\begin{array}{c}\text { P Uygulamas1 } \\
\mathrm{mg} \mathrm{kg}^{-1}\end{array}$ & Kuru Ağırlık g bitki ${ }^{-1}$ \\
\hline \multirow{4}{*}{ Marul } & 0 & $2.90 \mathrm{~b}^{*}$ \\
& 50 & $4.84 \mathrm{a}$ \\
& 100 & $3.29 \mathrm{~b}$ \\
& 200 & $3.52 \mathrm{~b}$ \\
& 400 & $3.57 \mathrm{~b}$ \\
\hline \multirow{4}{*}{ Soğan } & 0 & 0.74 \\
& 50 & $3.57 \mathrm{~b}$ \\
& 100 & $4.72 \mathrm{a}$ \\
& 200 & $4.72 \mathrm{a}$ \\
& 400 & $4.92 \mathrm{a}$ \\
“**Aynı harflerle gösterilen ortalamalar arası fark önemsizdir & $4.77 \mathrm{a}$ \\
\hline
\end{tabular}

Artan düzeyde fosfor uygulamalarının marul ve soğan bitkilerinin kuru ağırlıkları üzerine etkisi Tablo 2'de verilmiştir. Marul bitkisinde en yüksek kuru ağırlığa $50 \mathrm{mg} \mathrm{kg}^{-1} \mathrm{P}$ uygulamasında ulaşılmıştır. Soğan bitkisinin kuru ağırlık miktarı kontrole göre artmış ve P dozları arası fark istatistiki olarak önemsiz olmuştur.

Tablo 3. Artan düzeyde uygulanan fosforun marul ve soğan bitkilerinin $\mathrm{P}, \mathrm{K}, \mathrm{Ca}, \mathrm{Mg}$ konsantrasyonları $\left(\mathrm{g} \mathrm{kg}^{-1}\right)$ üzerine etkisi

\begin{tabular}{cccccc}
\hline Bitki & $\begin{array}{c}\text { P Uygulamas1 } \\
\text { mg kg }^{-1}\end{array}$ & P & K & Ca & Mg \\
\hline \multirow{4}{*}{ Marul } & 0 & $1.57 \mathrm{c}$ & 62.45 & $14.08 \mathrm{ab}$ & 3.36 \\
& 50 & $2.75 \mathrm{~b}$ & 65.49 & $11.46 \mathrm{~b}$ & 3.53 \\
& 100 & $4.57 \mathrm{a}$ & 69.53 & $16.08 \mathrm{a}$ & 3.84 \\
& 200 & $4.74 \mathrm{a}$ & 62.59 & $14.60 \mathrm{ab}$ & 3.32 \\
\hline
\end{tabular}


Nevşehir Bilim ve Teknoloji Dergisi TARGíD Özel Sayı 150-160 2016

\begin{tabular}{cccccc}
\hline & LSD $\mathrm{p}<0.05$ & 0.54 & ö.d & 3.12 & ö.d \\
\hline \multirow{4}{*}{ Soğan } & 0 & $1.47 \mathrm{e}$ & $44.26 \mathrm{~b}$ & 11.37 & 2.33 \\
& 50 & $2.19 \mathrm{~d}$ & $52.15 \mathrm{a}$ & 12.03 & 2.32 \\
& 100 & $2.71 \mathrm{c}$ & $52.14 \mathrm{a}$ & 12.47 & 2.34 \\
& 200 & $3.40 \mathrm{~b}$ & $52.23 \mathrm{a}$ & 12.35 & 2.34 \\
\hline & 400 & $4.02 \mathrm{a}$ & $53.56 \mathrm{a}$ & 12.39 & 2.42 \\
\hline
\end{tabular}

“Harfler yukarıdan aşağıya Duncanları vermektedir. ö.d: önemli değil”

Marul ve soğan bitkilerinin P konsantrasyonlarında artan fosfor uygulamalarına bağlı olarak artış olduğu belirlenmiştir. Marul bitkisinde Ca konsantrasyonunun en yüksek olduğu uygulama $100 \mathrm{mg} \mathrm{kg}^{-1} \mathrm{P}$ olmuştur. Soğan bitkisinin K konsantrasyonu kontrole göre artmış ancak P düzeyleri arası fark önemsiz olmuştur (Tablo 3). Fosfor uygulamasının marul bitkisinde $\mathrm{K}$ ve $\mathrm{Mg}$, soğan bitkisinde ise $\mathrm{Ca}$ ve $\mathrm{Mg}$ konsantrasyonları üzerine etkisi önemsiz olmuştur.

Tablo 4. Artan düzeyde uygulanan fosforun marul ve soğan bitkilerinin $\mathrm{S}, \mathrm{Na}, \mathrm{Cl}$ ve Si konsantrasyonları ( $\left.\mathrm{g} \mathrm{kg}^{-1}\right)$ üzerine etkisi

\begin{tabular}{|c|c|c|c|c|c|}
\hline Bitki & $\begin{array}{c}\text { P Uygulaması } \\
\mathrm{mg} \mathrm{kg}^{-1}\end{array}$ & $S$ & $\mathrm{Na}$ & $\mathrm{Cl}$ & $\mathrm{Si}$ \\
\hline \multirow{6}{*}{ Marul } & 0 & $3.17 \mathrm{a}$ & 1.59 & 7.38 & $5.15 \mathrm{a}$ \\
\hline & 50 & $2.94 \mathrm{abc}$ & 1.62 & 7.23 & $2.77 \mathrm{~b}$ \\
\hline & 100 & $3.09 \mathrm{ab}$ & 0.84 & 5.46 & $2.35 \mathrm{~b}$ \\
\hline & 200 & 2.77 bc & 0.76 & 6.01 & $2.44 \mathrm{~b}$ \\
\hline & 400 & $2.60 \mathrm{c}$ & 0.57 & 5.62 & $1.52 \mathrm{~b}$ \\
\hline & LSD $p<0.05$ & 0.38 & ö.d & ö.d & 1.35 \\
\hline \multirow{6}{*}{ Soğan } & 0 & $4.64 \mathrm{~b}$ & 1.20 & 6.39 & 1.18 \\
\hline & 50 & $5.95 \mathrm{a}$ & 1.50 & 7.43 & 1.17 \\
\hline & 100 & 5.98 a & 1.47 & 7.59 & 1.10 \\
\hline & 200 & $5.91 \mathrm{a}$ & 1.32 & 7.33 & 1.00 \\
\hline & 400 & $5.98 \mathrm{a}$ & 1.66 & 7.54 & 1.08 \\
\hline & LSD $p<0.05$ & 0.42 & ö.d & ö.d & ö.d \\
\hline
\end{tabular}

Artan düzeyde $\mathrm{P}$ uygulamaları ile kontrol kıyaslandığında, marul bitkisin $\mathrm{S}$ ve $\mathrm{Si}$ konsantrasyonunda düşüş, soğan bitkisinin S konsantrasyonunda artış olduğu belirlenmiştir. Her iki bitkinin Na ve Cl konsantrasyonları ile soğan bitkisinin Si konsantrasyonunda istatistikî olarak önemli bir fark belirlenmemiştir (Tablo 4)

Tablo 5. Artan düzeyde uygulanan fosforun marul ve soğan bitkilerinin $\mathrm{Fe}, \mathrm{Zn}, \mathrm{Cu}, \mathrm{Mn}$ ve Mo konsantrasyonları (mg kg-1) üzerine etkisi

\begin{tabular}{|c|c|c|c|c|c|c|}
\hline Bitki & $\begin{array}{l}\text { P Uygulaması } \\
\text { mg kg-1 }^{-1}\end{array}$ & $\mathrm{Fe}$ & Zn & $\mathrm{Cu}$ & $\mathrm{Mn}$ & Mo \\
\hline \multirow{6}{*}{ Marul } & 0 & $776 \mathrm{a}$ & $37.10 \mathrm{a}$ & 10.53 & $73.67 \mathrm{a}$ & 2.53 \\
\hline & 50 & $417 \mathrm{~b}$ & $14.77 \mathrm{~b}$ & 7.30 & $72.30 \mathrm{a}$ & 2.23 \\
\hline & 100 & $461 \mathrm{~b}$ & $16.30 \mathrm{~b}$ & 8.67 & $66.00 \mathrm{ab}$ & 2.87 \\
\hline & 200 & $488 \mathrm{~b}$ & $16.97 \mathrm{~b}$ & 9.33 & $43.33 \mathrm{c}$ & 2.53 \\
\hline & 400 & $208 \mathrm{c}$ & $15.57 \mathrm{~b}$ & 8.47 & 49.67 bc & 2.67 \\
\hline & LSD $p<0.05$ & 203.20 & 3.63 & ö.d & 18.07 & ö.d \\
\hline \multirow{6}{*}{ Soğan } & 0 & $104.00 \mathrm{a}$ & 11.25 & $12.08 \mathrm{a}$ & 43.00 & 2.63 \\
\hline & 50 & $82.75 b$ & 11.13 & 7.33 c & 46.08 & 2.75 \\
\hline & 100 & $83.00 \mathrm{~b}$ & 11.75 & 7.35 c & 43.48 & 2.38 \\
\hline & 200 & $76.00 \mathrm{~b}$ & 11.95 & 7.28 c & 40.45 & 2.78 \\
\hline & 400 & $76.00 \mathrm{~b}$ & 11.83 & $8.88 \mathrm{~b}$ & 42.30 & 2.63 \\
\hline & LSD $p<0.05$ & 16.09 & ö.d & 1.25 & ö.d & ö.d \\
\hline
\end{tabular}

Artan düzeyde $\mathrm{P}$ uygulamalarına bağlı olarak marul bitkisinin $\mathrm{Fe}, \mathrm{Zn}$ ve $\mathrm{Mn}$ konsantrasyonlarında ve soğan bitkisinin ise $\mathrm{Fe}$ ve $\mathrm{Cu}$ konsantrasyonlarında düşüş olduğu belirlenmiştir. 
Her iki bitkinin Mo konsantrasyonu ile marul bitkisinin $\mathrm{Cu}$ ve soğan bitkisinin ise $\mathrm{Zn}$ ve $\mathrm{Mn}$ konsantrasyonları üzerine P uygulamalarının etkisi önemsiz olmuştur (Tablo 5).

Tablo 6. Artan düzeyde uygulanan fosforun marul ve soğan bitkilerinin $\mathrm{Al}\left(\mathrm{g} \mathrm{kg}^{-1}\right)$, Ti, Co ve Ni (mg kg$\left.{ }^{-1}\right)$ konsantrasyonları üzerine etkisi

\begin{tabular}{|c|c|c|c|c|c|}
\hline Bitki & $\begin{array}{c}\text { P Uygulaması } \\
\mathrm{mg} \mathrm{kg}^{-1}\end{array}$ & $\mathrm{Al}$ & $\mathrm{Ti}$ & Co & $\mathrm{Ni}$ \\
\hline \multirow{6}{*}{ Marul } & 0 & 1.45 & $74.30 \mathrm{a}$ & 3.43 & $5.60 \mathrm{a}$ \\
\hline & 50 & 0.63 & $54.67 \mathrm{~b}$ & 2.40 & $3.67 \mathrm{~b}$ \\
\hline & 100 & 0,75 & $49.00 \mathrm{~b}$ & 2.33 & $3.87 \mathrm{~b}$ \\
\hline & 200 & 0.76 & $48.33 \mathrm{~b}$ & 3.70 & $3.93 \mathrm{~b}$ \\
\hline & 400 & 0.54 & $24.00 \mathrm{c}$ & 1.87 & $2.90 \mathrm{~b}$ \\
\hline & LSD $p<0.05$ & ö.d & 19.20 & ö.d & 1.68 \\
\hline \multirow{6}{*}{ Soğan } & 0 & 0.52 & $18.60 \mathrm{a}$ & $2.45 \mathrm{a}$ & $4.40 \mathrm{a}$ \\
\hline & 50 & 0.48 & $12.68 \mathrm{~b}$ & $1.98 \mathrm{ab}$ & $3.68 \mathrm{ab}$ \\
\hline & 100 & 0.50 & $12.80 \mathrm{~b}$ & $1.63 \mathrm{bc}$ & $3.78 \mathrm{ab}$ \\
\hline & 200 & 0.46 & $7.53 \mathrm{c}$ & $1.33 \mathrm{c}$ & $3.20 \mathrm{~b}$ \\
\hline & 400 & 0.43 & $4.20 \mathrm{c}$ & 1.45 bc & $3.23 \mathrm{~b}$ \\
\hline & LSD $p<0.05$ & ö.d & 4.08 & 0.59 & 0.76 \\
\hline
\end{tabular}

Marul ve soğan bitkilerinin Ti ve Ni konsantrasyonları ile soğan bitkisinin Co konsantrasyonu artan P uygulamalarına bağlı olarak azalmıştır (Tablo 6). Her iki bitkinin Al konsantrasyonu ile marul bitkisinin Co konsantrasyonu uygulanan P düzeylerinden etkilenmemiştir.

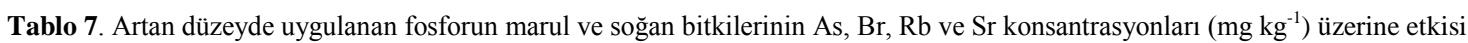

\begin{tabular}{cccccc}
\hline Bitki & $\begin{array}{c}\text { P Uygulamas1 } \\
\mathrm{mg} \mathrm{kg}^{-1}\end{array}$ & As & $\mathrm{Br}$ & $\mathrm{Rb}$ & $\mathrm{Sr}$ \\
\hline \multirow{4}{*}{ Marul } & 0 & 0.32 & $8.67 \mathrm{c}$ & $7.83 \mathrm{~d}$ & $86.50 \mathrm{a}$ \\
& 50 & 0.63 & $10.50 \mathrm{bc}$ & $12.83 \mathrm{c}$ & $82.77 \mathrm{a}$ \\
& 100 & 0.67 & $10.97 \mathrm{~b}$ & $15.53 \mathrm{~b}$ & $70.37 \mathrm{~b}$ \\
& 200 & 0.61 & $11.00 \mathrm{~b}$ & $13.43 \mathrm{c}$ & $77.73 \mathrm{ab}$ \\
& 400 & 0.63 & $13.53 \mathrm{a}$ & $19.33 \mathrm{a}$ & $71.63 \mathrm{~b}$ \\
\hline \multirow{5}{*}{ Soğan } & LSD p $<0.05$ & $0 . \mathrm{d}$ & 2.04 & 2.09 & 10.23 \\
& 0 & $0.30 \mathrm{c}$ & $32.88 \mathrm{c}$ & $8.23 \mathrm{c}$ & $61.30 \mathrm{c}$ \\
& 50 & $0.31 \mathrm{c}$ & $36.00 \mathrm{bc}$ & $10.63 \mathrm{~b}$ & $65.70 \mathrm{bc}$ \\
& 100 & $0.70 \mathrm{~b}$ & $34.65 \mathrm{bc}$ & $11.00 \mathrm{~b}$ & $69.28 \mathrm{~b}$ \\
& 200 & $0.80 \mathrm{~b}$ & $37.02 \mathrm{~b}$ & $11.22 \mathrm{~b}$ & $69.42 \mathrm{~b}$ \\
& 400 & $1.12 \mathrm{a}$ & $44.80 \mathrm{a}$ & $12.34 \mathrm{a}$ & $75.03 \mathrm{a}$ \\
\hline
\end{tabular}

Fosfor uygulaması, soğan bitkisinin As, $\mathrm{Br}, \mathrm{Rb}$ ve Sr konsantrasyonlarını artırmıştır (Tablo 7). Fosfor uygulaması, marul bitkisinin As içeriğinde önemli bir değişime neden olmazken $\mathrm{Br}$ ve $\mathrm{Rb}$ konsantrasyonlarını artırmış, Sr konsantrasyonun ise azaltııştır.

Tablo 8. Artan düzeyde uygulanan fosforun marul ve soğan bitkilerinin $\mathrm{Cd}, \mathrm{Ba}$, Th ve U konsantrasyonları (mg kg-1) üzerine etkisi

\begin{tabular}{|c|c|c|c|c|c|}
\hline Bitki & $\begin{array}{c}\text { P Uygulamas1 } \\
\mathrm{mg} \mathrm{kg}^{-1}\end{array}$ & $\mathrm{Cd}$ & $\mathrm{Ba}$ & Th & $\mathrm{U}$ \\
\hline \multirow{6}{*}{ Marul } & 0 & 0.73 & 39.33 a & 0.67 & 3.53 \\
\hline & 50 & 0.90 & $25.57 \mathrm{~b}$ & 1.07 & 5.13 \\
\hline & 100 & 0.83 & $29.67 \mathrm{~b}$ & 1.17 & 4.30 \\
\hline & 200 & 0.83 & $32.83 \mathrm{ab}$ & 1.07 & 4.20 \\
\hline & 400 & 0.87 & $24.37 \mathrm{~b}$ & 1.17 & 4.47 \\
\hline & LSD $\mathrm{p}<0.05$ & ö.d & 8.95 & ö.d & ö.d \\
\hline \multirow{6}{*}{ Soğan } & 0 & $0.68 \mathrm{c}$ & $8.88 \mathrm{~b}$ & 0.98 & $3.00 \mathrm{c}$ \\
\hline & 50 & $0.88 \mathrm{a}$ & $9.13 \mathrm{~b}$ & 0.93 & $5.88 \mathrm{a}$ \\
\hline & 100 & 0.75 abc & $17.98 \mathrm{a}$ & 0.73 & $3.53 \mathrm{c}$ \\
\hline & 200 & 0.73 bc & 17.98 a & 0.68 & $3.90 \mathrm{bc}$ \\
\hline & 400 & $0.85 \mathrm{ab}$ & $15.00 \mathrm{a}$ & 0.80 & $4.70 \mathrm{~b}$ \\
\hline & LSD $\mathrm{p}<0.05$ & 0.14 & 5.22 & ö.d & 1.02 \\
\hline
\end{tabular}


Marul bitkisinin Ba konsantrasyonunu $\mathrm{P}$ uygulaması kontrole göre azaltmıştır. Fosfor uygulamasına bağlı olarak soğan bitkisinin $\mathrm{Cd}$ ve $\mathrm{Ba}$ konsantrasyonları kontrole göre artmış, $\mathrm{U}$ konsantrasyonu ise 50 ve $400 \mathrm{mg} \mathrm{kg}^{-1} \mathrm{P}$ düzeylerinde artmıştır (Tablo 8).

\section{Tartışma ve Sonuç}

$\mathrm{Bu}$ çalışmadan elde edilen bulgulara göre $\mathrm{P}$ uygulaması genel olarak marul ve soğan bitkilerinin kuru ağırlıklarını artırmıştır. Artan P uygulamasına bağlı olarak ayçiçeği [35] ve domatesinde [37] kuru ağırlığının arttığı bildirilmiştir. Bitkilerin P konsantrasyonları artan P uygulamalarına bağlı olarak artış göstermekte bu sonuç [35] tarafindan yapılan çalışma ile benzerlik göstermektedir. Fosforlu gübrelerin topraklarda ağır metal artışına neden oldukları bilinmektedir [18 ve 21]. Marul bitkisine uygulanan P ile bitkinin $\mathrm{Br}, \mathrm{Rb}$ konsantrasyonlarının arttığı [35], Ca, S, Fe, Zn, Mn, Ti ve Sr konsantrasyonlarının azaldığı bildirilmiştir [3 ve 35]. Soğan bitkisine artan düzeyde uygulanan P'a bağlı olarak bitkilerin As, $\mathrm{Rb}, \mathrm{Sr}, \mathrm{Ba}$ konsantrasyonları artmış $\mathrm{Cu}$, Ti ve Co konsantrasyonları azalmıştır [35 ve 38].

Türkiye'de bilinçsizce ve aşırı miktarda kullanılan P'lu gübreler topraklarda ağır metal konsantrasyonlarının artışına sebep olmakta [39] ve bitkiler tarafından toksik miktarda alınan bu metaller insan sağlığı üzerine olumsuz etki yapmaktadır. Eser miktarda bulunması gereken ağır metallerin aşırı miktarları özellikle karaciğer, sinir sistemi ile kalp ve damar hastalıklarının arışıına neden olmaktadır [40 ve 41]. Ayrıca aşırı miktarda uygulanan P'lu gübreler ile bitkilerin Fe, $\mathrm{Zn}$ ve Mn konsantrasyonlarında meydana gelen azalma hem bitki gelişimini olumsuz etkilemekte hem de insan sağlığı açısından önemli olan enzimlerin çalışması üzerine olumsuz etki yapmaktadır [21 ve 35].

Bu çalışma, bitkilerin gelişiminde önemli etkiye sahip olan P'un aşırı miktarda kullanılması ile topraklarda ve bitkilerde ağır metal konsantrasyonlarının artabileceğini ve mikro element konsantrasyonlarının azalabileceğini ortaya koymuştur. Ağır metaller bitki gelişimini etkilemekte ve bu bitkilerle beslenen canlıların sağlığı üzerine de olumsuz etkilerde bulunduğundan ağır metal bulaşmasına neden olabilecek aşırı P'lu gübre kullanımından kaçınılması gerekmektedir. Diğer taraftan P kaynaklarının günden güne azaldığı dünyamızda P'u daha etkin kullanan bitki çeşitlerinin seçilmesinin daha etkili ve çevreci bir yöntem olabileceği düşünülmektedir.

\section{Kaynaklar}

[1] Brinck J.N., "World Resources of Phosphorus. In: Phosphorus in the Environment: Its Chemistry and Biochemistry” Ciba Faundation Sym, 57, 23- 63, 1978

[2] Korkmaz K., "Kireçli Toprakların Fosfor Durumlarının Belirlenmesi ve fosfor Uygulamasının Mısır Verimine Etkisi” Çukurova Üniversitesi, Fen Bilimleri Enstitüsü, Doktora Tezi,136s, Adana, 2005

[3] Güneş A., Alpaslan M., İnal, A., "Bitki Besleme ve Gübreleme” Ankara Üniversitesi Ziraat Fakültesi Yayınları, 1514, 307, 2000

[4] Eyüboğlu F., "Türkiye Topraklarının Verimlilik Durumu” T.C. Başbakanlık KHGM, Toprak ve Gübre Araştırma Enst. Md. Yayınları. Genel Yayın No: 220, Teknik Yayın No: T-67,1999

[5] Özyağcı M.A., Aydoğan M., Bayraklı B., Kesim E., Şeker F., Dengiz O., Urla Ö., Yıldız H., Ünal E. "Orta ve Doğu Karadeniz Bölgesi Tarım Topraklarının Bitki Besin Maddesi ve 
Potansiyel Toksik Element Kapsamlarının Belirlenmesi, Veri Tabanının Oluşturulması ve Haritalanması”, GTHB, Karadeniz Tarımsal Araştırma Enst. Müd. TAGEM-BB-08020201H1, Samsun, 2013

[6] Mengel K., Kirkby E.A., "Principles of Plant Nutrition” 4. ed. Int. Potash. Inst. Inst. Bern, Switzerland, 655, 1987

[7] Rodriguez D., Andrade F.H., Goudriaan, J., "Does Assimilate Supply Limit Phosphorus Availability”, Field Crops Research, 67, 227-238, 2000

[8] Gallet A., Flish R., Ryser J., Frossard E., Sinaj S., "Effect of Phosphate Fertilization on Crop Yield and Soil Phosphorus Status”, Jounal of Plant Nutrition Science, 166, 568-578, 2003

[9] Fransson A., Aarle I.M., Olsson P.A., Tyler G., "Plantago Lanceolata L. Phosphorus Fractions”, Plant and Soil, 248, 285-295, 2003

[10] Gahoonia T.S., Nielsen E.N., Ole B.L., "Phosphorus (P) Acquisition of Cerea Fertilization”, Plant and Soil, 211, 269-281, 1999

[11] Holford I.C.R., “Soil Phosphorus- Its Measurement and Its Uptake by Plants”, Australian Journal Soil Research, 35, 227-239, 1997

[12] Richardson A.E., "Soil Microorganisms and Phosphorus Avability”, Soil Biota, 17, 50-62, 1994

[13] Daroub S.H., Gerakis A., Itchie J.T., Friesen K.D., Ryan, J., “Development of a Soil-Plant Phosphorus and Weathered Tropical Soils”, Agricultural Systems, 76, 1157-1181, 2003

[14] Leytem A.B., Westermann D.T., "Phosphate Sorption by Pacific Northwest Calcareous Soils”, Soil Science, 168, 368-375, 2003

[15] Shibata R., Yano, K., "Phosphorus Acquisition from Non-Labile Sources in Peanut and Pigeonpea with Mycorrhizal Interaction”, Applied Soil Ecology, 24, 133-141, 2003

[16] Zhu Y., Smith F.A., Smith S.E., "Phosphorus Efficiencies and Responses of Barley (Hordeum vulgare L.) to Arbuscular Mycorrhizal Fungi Grown in Highly Calcareous Soil”, Mycorrhiza, 13, 93-100, 2003

[17] Shin H., Shin H. S., Dewbre G.R., Harrison M., Transport in Arabidopsis: Pht1;1 and Pht1; 4 play a major Role in Phosphate Acquisition from Both Low and High Phosphate Environments”, The Plant Journal, 39, 629-642, 2004

[18] Köleli, N., Kantar Ç., Fosfat kayası, Fosforik Asit ve Fosforlu Gübrelerdeki Toksik Ağır Metal (Cd, Pb, Ni, As) Konsantrasyonu”, Ekoloji, 55, 1-5, 2005

[19] Mortvedt J.J., Beaton J.D. , "Heavy Metal and Radionuclide Contaminantants in Phosphate Fertilizers”, Phosphorus in the Global Environment - chap 6, 1-14, 2001

[20] Nanthi S.B., Domy C.A., Ravi N., "Role of Phosphorus in (Im)Mobilization and Mioavailability of Heavy Metals in the Soil-Plant System”, Reviews Environmental Contaminatian and Toxicology, 177, 1-44, 2003

[21] Sabiha- Javied T.M., Chaudhry M.M., Tufail M., Irfan N., "Heavy Metal Pollution from phosphate Rock Used for the Production of Fertilizer in Pakistan”, Microchemical Journal, 91, 94-99, 2009 
[22] Atafar Z., Mesdaghinia A., Nouri J., Homaee M., Yunesian M., Ahmadimoghaddam M., Mahvi A.H., "Effect of Fertilizer Application on Soil Heavy Metal Concentration", Environmental Monitoring and Assessment, 160, 83-89, 2010

[23] Alpaslan M., Güneş A., İnal A., "Deneme Tekniği”, Ankara Üniversitesi Ziraat Fakültesi Yayın No: 1501, 455, Ankara, 1998.

[24] Anonymous, "Soil Survey Stuff", Soil Survey Manual. Agric. Res. Administration, USDA Handbook, 18, 340-37, 1951

[25] Bouyoucos G.J.A., "Realibration of Hydrometer for Making Mechanical Analysis of Soil", Agronomy Journal, 43, 434-438, 1951

[26] Anonymous, "Soil Survey Division Staff”, Soil survey manual, Soil Conservation Service, U.S. Department of Agriculture Handbook, 18, 1993

[27] Jackson M.L., "Soil Chemical Analysis”, Prentice-Hall, Inc. Englewood Cliffs, New Jersey, USA, 1-498, 1958

[28] Richards L.A., "Diagnosis and Improvement of Saline and Alkaline Soils”, U.S. Dept. of Agr. Handbook No: 60, 1954

[29] Hızalan E., Ünal H., “Topraklarda Önemli Kimyasal Analizler”, Ankara Üniversitesi Ziraat Fakültesi Yayınları, 278, 1966.

[30] Bremner J.M., "Total Nitrogen Methods of Soil Analysis .Part 2.Chemical and Microbiological Properties”, Ed. C. A. Black. Amer. Soc.of Agron. Inc. Pub. Agron.Series, No: 9, Madison, Wisconsin, U.S.A. 1149-117, 1965

[31] Olsen S.R., Cole C.V., Watanabe F.S., Dean N.C., "Estimation of Available Phosphous in Soil by Extraction with Sodium Bicorbonate”, U. S. Dept.of Agr.Cir., 939, Washington. D. C, 1954

[32] Pratt P.F., "Methods of Soil Analysis Part 2. Chemical and Microbiological Properties" ed.c. a. black. American Sociol of Agronomy. Inc. Pub. Agron, Series No. 9, 1965

[33] Lindsay W.L., Norvell W.A., "Development of a DTPA Micronutrient Soil Test”, Soil Scien Society of American Proceding, 35, 600-602, 1969

[34] Gunes, A. Inal, A., Kadioglu, Y.K., "Determination of Mineral Element Concentrations in Wheat, Sunflower, Chickpea and Lentil Cultivars in Response to P Fertilization by Polarized Energy Dispersive X-ray ffuorescence”, X-Ray Spectrometry, 38, 451-462, 2009

[35] Gunes A., Inal A Bagc1 E.G., Kadioglu Y.K., "Combined Effect of Arsenic and Phosphorus on Mineral Element Concentrations of Sunflower", Communications in Soil Science and Plant Analysis, 41, 361-372, 2010

[36] Chuparina E.V., Gunicheva T.N., "Nondestructive X-ray Fluorescence Determination of Some Elements in Plant Material”, Journal of Analytical Chemistry, 58, 856-861, 2003

[37] Malak A.E.R., Al-Ashkar A.E., The effect of Different Fertilizers on the Heavy Metals in Soil and Tomato Plant, Australian Journal of Basic and Applied Science, 1, 300-306, 2007

[38] Zhang M.K., He Z.L., Calvert D.V., Stofella P.J., Yang X.F., Lamb E.M., “Accumulation and Partitioning of Phosphorus and Heavy Metals in a Sandy Soil Under Long-Term Vegetable Crop Production”, Journal of Environmental Science and Health, 38, 1991-1995, 2003 
[39] Sönmez İ, Kaplan M., Sönmez S., "Kimyasal Gübrelerin Çevre Kirliliği Üzerine Etkileri ve Çözüm Önerileri”, Batt Akdeniz Tarımsal Araştırma Enstitüsü Derim Dergisi, 25, 24-34, 2008

[40] Okçu M., Tozlu E., Kumlay A.M., Pehluvan M., “Ağır Metallerin Bitkiler Üzerine Etkileri”, Alinteri, 17(B), 14-26, 2009

[41] Bağdatı̆ığlu, N., Nergiz C., Ergönül P.G., “ Genellikle Salata Olarak Tüketilen Bazı Yeşil Sebzelerde Kurşun ve Kadmiyum Düzeylerinin Araştırılması”, Türkiye 10. Gıda Kongresi, 21-23 Mayıs 2008, Erzurum, 2008 